\title{
Solubility of Anthracene in Binary Alkane + Methyl tert-Butyl Ether Solvent Mixtures at 298.15 K
}

\author{
Mary E. R. McHale, Ann-Sofi M. Kauppila, and William E. Acree, J r.* \\ Department of Chemistry, University of North Texas, Denton, Texas 76203-0068
}

\begin{abstract}
Experimental solubilities are reported for anthracene dissolved in seven binary mixtures containing methyl tert-butyl ether (also called 2-methoxy-2-methylpropane) with hexane, heptane, octane, cyclohexane, methylcyclohexane, 2,2,4-trimethylpentane, and tert-butylcyclohexane (also called (1,1-dimethylethyl)cyclohexane) at $25^{\circ} \mathrm{C}$. Results of these measurements are used to test two mathematical representations based upon the combined nearly ideal binary solvent (NIBS)/Redlich-Kister equation and modified Wilson model. For the seven systems studied, both equations were found to provide an accurate mathematical representation of the experimental data, with an overall average absolute deviation between measured and calculated values being on the order of $0.5 \%$.
\end{abstract}

\section{Introduction}

Solid-liquid equilibrium data of organic nonelectrolyte systems are becoming increasingly important in the petroleum industry, particularly in light of present trends toward heavier feedstocks and known carcinogenicity/ mutagenicity of many of the larger polycyclic aromatic compounds. Solubility data for a number of polycyclic aromatic hydrocarbons (e.g., anthracene and pyrene) and heteroatom polynuclear aromatics (e.g., carbazole, dibenzothiophene, and xanthene) have been published in the recent chemical literature (for listing of references see: Acree, 1994, 1995a,b). Despite efforts by experimentalists and scientific organizations, both in terms of new experimental measurements and critically-evaluated data compilations, there still exist numerous systems for which solubility data are not readily available.

To address this problem, researchers have turned to group contribution methods and semiempirical expressions to predict desired quantities. Group contribution methods have proved fairly successful in estimating solid solubility in pure and binary solvent mixtures from structural information. Practical application, though, is limited to systems for which all group interaction parameters are known. Interaction parameters can be evaluated from liquid-vapor, liquid-liquid, and solid-liquid equilibria data. It is important that the data base contain as many different functional groups as possible, preferably with adequate representation from both mono- and multifunctional solute/solvent molecules to permit evaluation of potential synergistic effects. The data base should contain sufficient experimental values near infinite dilution in the event that one wishes to determine separate interaction parameters for finite concentration and infinite dilution activity coefficient predictions.

Continued development of solution models for describing the thermodynamic properties of a solute in binary solvent systems requires that a large data base be available for assessing the applications and limitations of derived expressions. Currently, only a limited data base exists for crystalline nonelectrolyte solubility in binary solvent mixtures. For this reason, anthracene solubilities were determined in seven binary alkane + methyl tert-butyl ether solvent mixtures. Results of these measurements are used

* To whom correspondence should be addressed. E-mail: acree@ casl.unt.edu. to further test the descriptive abilities of several previously derived expressions.

\section{Experimental Methods}

Anthracene (Gold Label, Aldrich 99.9+\%) was used as received. Cyclohexane (Aldrich, HPLC), hexane (Aldrich, 99\%), heptane (Aldrich, HPLC), octane (Aldrich, 99+\%, anhydrous), methylcyclohexane (Aldrich, 99+\%, anhydrous), 2,2,4-trimethylpentane (Aldrich, HPLC), tert-butylcyclohexane (Aldrich, 99\%, also called (1,1-dimethylethyl)cycl ohexane), and methyl tert-butyl ether (Arco, 99.9+\%, also called 2-methoxy-2-methylpropane) were stored over molecular sieves before being fractionally distilled. Gas chromatographic analysis showed solvent purities to be $99.7 \mathrm{~mol} \%$ or better. Binary solvent mixtures were prepared by mass so that compositions could be calculated to 0.0001 mole fraction.

Excess solute and solvent were placed in amber glass bottles and allowed to equilibrate in a constant temperature water bath at $(25.0 \pm 0.1){ }^{\circ} \mathrm{C}$ for at least 3 days (often longer). Attainment of equilibrium was verified both by repetitive measurements after a minimum of 3 additional days and by approaching equilibrium from supersaturation by pre-equilibrating the solutions at a higher temperature. Aliquots of saturated anthracene solutions were transferred through a coarse filter into a tared vol umetric flask to determine the amount of sample and diluted quantitatively with methanol for spectrophotometric analysis at 356 $\mathrm{nm}$ on a Bausch and Lomb Spectronic 2000. Concentrations of the dilute solutions were determined from a BeerLambert law absorbance versus concentration working curve. Molar absorptivities of the nine standard solutions varied systematically with molar concentration and ranged from circa $\epsilon /\left(\mathrm{L} \cdot \mathrm{mol}^{-1} \cdot \mathrm{cm}^{-1}\right)=7450$ to $\epsilon /\left(\mathrm{L} \cdot \mathrm{mol}^{-1} \cdot \mathrm{cm}^{-1}\right)=$ 7150 for anthracene concentrations ranging from $\mathrm{C} / \mathrm{M}=$ $6.75 \times 10^{-5}$ to $\mathrm{C} / \mathrm{M}=2.25 \times 10^{-4}$. Experimental molar concentrations were converted to (mass/mass) solubility fractions by multiplying by the molar mass of anthracene, volume(s) of volumetric flask(s) used, and any dilutions required to place the measured absorbances on the BeerLambert law absorbance versus concentration working curve and then dividing by the mass of the saturated solution analyzed. Mole fraction solubilities were computed from (mass/mass) solubility fractions using the binary solvent initial mole fraction compositions and molar masses of the solute and both cosolvents. Experimental 
Table 1. Experimental Mole Fraction Solubilities of Anthracene $\left(x_{A}^{\text {sat }}\right)$ in Binary Alkane $(B)+$ Methyl tert-Butyl Ether (C) Solvent Mixtures at $25.0^{\circ} \mathrm{C}$

\begin{tabular}{|c|c|c|c|}
\hline$x_{C}^{0}$ & $x_{A}^{\text {sat }}$ & $x_{C}^{0}$ & $x_{A}^{\text {sat }}$ \\
\hline $\begin{array}{l}0.0000 \\
0.1216 \\
0.2175 \\
0.4207 \\
0.5240\end{array}$ & $\begin{array}{c}\text { e (B) }+\mathrm{Me} \\
0.00127 \\
0.00144 \\
0.00159 \\
0.00197 \\
0.00218\end{array}$ & $\begin{array}{c}\text { t-Butyl E } \\
0.6328 \\
0.7979 \\
0.9058 \\
1.0000\end{array}$ & $\begin{array}{l}\text { C) } \\
0.00242 \\
0.00274 \\
0.00294 \\
0.00305\end{array}$ \\
\hline $\begin{array}{l}0.0000 \\
0.1425 \\
0.2263 \\
0.4551 \\
0.5581\end{array}$ & $\begin{array}{c}e(B)+M \\
0.00157 \\
0.00171 \\
0.00184 \\
0.00219 \\
0.00237\end{array}$ & $\begin{array}{r}r t-B u t y l \\
0.6492 \\
0.8292 \\
0.9098 \\
1.0000\end{array}$ & $\begin{array}{l}\text { C) } \\
0.00255 \\
0.00284 \\
0.00297 \\
0.00305\end{array}$ \\
\hline $\begin{array}{l}0.0000 \\
0.1376 \\
0.2592 \\
0.4711 \\
0.5759\end{array}$ & $\begin{array}{c}e(B)+M e \\
0.00184 \\
0.00198 \\
0.00211 \\
0.00239 \\
0.00255\end{array}$ & $\begin{array}{c}\text { t-Butyl E } \\
0.6774 \\
0.8451 \\
0.9173 \\
1.0000\end{array}$ & $\begin{array}{l}0.00272 \\
0.00292 \\
0.00301 \\
0.00305\end{array}$ \\
\hline $\begin{array}{r}C \\
0.0000 \\
0.0935 \\
0.1765 \\
0.3737 \\
0.4779\end{array}$ & $\begin{array}{c}\text { ane }(B)+1 \\
0.00155 \\
0.00174 \\
0.00195 \\
0.00242 \\
0.00258\end{array}$ & $\begin{array}{c}\text { tert-Buty } \\
0.5822 \\
0.7800 \\
0.9079 \\
1.0000\end{array}$ & $\begin{array}{l}(C) \\
0.00268 \\
0.00289 \\
0.00295 \\
0.00305\end{array}$ \\
\hline $\begin{array}{l}\quad \text { Meth } \\
0.0000 \\
0.1120 \\
0.2070 \\
0.4072 \\
0.5135\end{array}$ & $\begin{array}{c}\text { hexane }(B) \\
0.00165 \\
0.00189 \\
0.00208 \\
0.00245 \\
0.00265\end{array}$ & $\begin{array}{c}\text { hyl tert-B } \\
0.5953 \\
0.7875 \\
0.9008 \\
1.0000\end{array}$ & $\begin{array}{l}\text { ther }(C) \\
0.00277 \\
0.00298 \\
0.00303 \\
0.00305\end{array}$ \\
\hline $\begin{array}{l}2,2,4-\mathrm{Tr} \\
0.0000 \\
0.1411 \\
0.2681 \\
0.4838 \\
0.5787\end{array}$ & $\begin{array}{l}\text { Ipentane ( } \\
0.00107 \\
0.00120 \\
0.00138 \\
0.00175 \\
0.00194\end{array}$ & $\begin{array}{c}\text { ethyl tert } \\
0.6793 \\
0.8453 \\
0.9404 \\
1.0000\end{array}$ & $\begin{array}{r}\text { Ether }(C) \\
0.00217 \\
0.00264 \\
0.00291 \\
0.00305\end{array}$ \\
\hline $\begin{array}{l}\text { tert-Bu } \\
0.0000 \\
0.1560 \\
0.2707 \\
0.4880 \\
0.5887\end{array}$ & $\begin{array}{c}\text { ohexane (B } \\
0.00198 \\
0.00219 \\
0.00237 \\
0.00272 \\
0.00285\end{array}$ & $\begin{array}{c}\text { thyl tert- } \\
0.6928 \\
0.8487 \\
0.9207 \\
1.0000\end{array}$ & $\begin{array}{r}\text { Ether }(C) \\
0.00297 \\
0.00301 \\
0.00304 \\
0.00305\end{array}$ \\
\hline
\end{tabular}

anthracene solubilities in the seven binary alkane + methyl tert-butyl ether solvent mixtures studied are listed in Table 1. Numerical values represent the average of between four and eight independent determinations, with the measured values being reproducible to within $\pm 1.3 \%$.

\section{Results and Discussion}

Acree and co-workers (Acree and Zvaigzne, 1991; Acree et al., 1991; Acree 1992) suggested possible mathematical representations for isothermal solubility data based upon either a combined NIBS/Redlich-Kister model

$$
\ln x_{A}^{s a t}=x_{B}^{o} \ln \left(x_{A}^{s a t}\right)_{B}+x_{C}^{o} \ln \left(x_{A}^{s a t}\right)_{C}+x_{B}^{o} x_{C}^{o} \sum_{i=0}^{N} S_{i}\left(x_{B}^{o}-x_{C}^{o}\right)^{i}
$$

or modified Wilson equation (Comer and Kopecni, 1990)

$$
\begin{array}{r}
\ln \left[a_{A}(s) / x_{A}^{s a t}\right]=1-x_{B}^{o}\left\{1-\ln \left[a_{A}(s) /\left(x_{A}^{s a t}\right)_{B}\right]\right\} /\left(x_{B}^{o}+\right. \\
\left.\quad x_{C}^{o} \Lambda_{B C}^{\text {adj }}\right)-x_{C}^{o}\left\{1-\ln \left[a_{A}(s) /\left(x_{A}^{s a t}\right)_{C}\right]\right\} /\left(x_{B}^{o} \Lambda_{C B}^{\text {adj }}+x_{C}^{o}\right)
\end{array}
$$

where the various $S_{i}$ and $\Lambda_{i j}^{\text {adj }}$ "curve-fit" parameters can be evaluated via least squares analysis. In eqs 1 and 2 $x_{B}^{0}$ and $x_{C}^{0}$ refer to the solvent mole fraction composition (calculated as if the solute were not present), $a_{A}(s)$ is the activity of the solid solute, and $\left(x_{A}^{\text {sat }}\right)_{i}$ is the saturated mole fraction solubility of the solute in pure solvent $i$. The solute activity is defined as the ratio of the fugacity of the solid to the fugacity of the hypothetical pure supercooled liquid solute. The numerical value of $a_{A}(s)=0.01049$ (Acree and Rytting, 1983) used in the modified Wilson computations was calculated from

$$
\text { In } \mathrm{a}_{\mathrm{A}}(\mathrm{s})=-\Delta_{\text {fus }} \mathrm{H}_{\mathrm{A}}\left(\mathrm{T}_{\mathrm{mp}}-\mathrm{T}\right) /\left(\mathrm{RTT}_{\mathrm{mp}}\right)
$$

the molar enthalpy of fusion, $\Delta_{\text {fus }} \mathrm{H}_{\mathrm{A}} / \mathrm{J} \mathrm{mol}^{-1}=28860$ (Weast, 1983), at the normal melting point temperature of the solute, $\mathrm{T}_{\mathrm{mp}} / \mathrm{K}=490.0$. The above expression assumes that the molar enthalpy of fusion is independent of temperature over the range of $\mathrm{T} / \mathrm{K}=490.0-298.2$.

The ability of eqs 1 and 2 to mathematically represent the experimental solubility of anthracene in the seven binary alkane + methyl tert-butyl ether solvent systems is summarized in Table 2 in the form of "curve-fit" parameters and percent deviations in back-calculated solubilities. Careful examination of Table 2 reveals that both equations provide an accurate mathematical representation for how the solubility of anthracene varies with solvent composition. For the seven anthracene systems studied, the overall average absolute deviation between experimental and calculated values is $0.4 \%$ and $0.6 \%$ for eqs 1 and 2, respectively, which is less than the experi-

\begin{tabular}{|c|c|c|c|c|}
\hline \multirow[b]{2}{*}{ binary solvent system component (B) + component (C) } & \multicolumn{2}{|c|}{ eq 1} & \multicolumn{2}{|c|}{ eq 2} \\
\hline & $\mathrm{S}_{\mathrm{i}}^{\mathrm{a}}$ & $\% \operatorname{dev}^{b}$ & $\Lambda_{\mathrm{ij}}^{\mathrm{adj}} \mathrm{c}$ & $\% \operatorname{dev}^{b}$ \\
\hline hexane + methyl tert-butyl ether & $\begin{array}{r}0.318 \\
-0.244\end{array}$ & 0.2 & $\begin{array}{l}1.020 \\
3.860\end{array}$ & 0.4 \\
\hline heptane + methyl tert-butyl ether & $\begin{array}{r}0.149 \\
-0.268\end{array}$ & 0.5 & $\begin{array}{l}0.862 \\
3.857\end{array}$ & 0.5 \\
\hline octane + methyl tert-butyl ether & $\begin{array}{r}0.116 \\
-0.203 \\
0.098\end{array}$ & 0.2 & $\begin{array}{l}0.783 \\
4.081\end{array}$ & 0.3 \\
\hline cyclohexane + methyl tert-butyl ether & $\begin{array}{r}0.741 \\
0.174 \\
-0.365\end{array}$ & 0.7 & $\begin{array}{l}3.763 \\
0.100\end{array}$ & 1.2 \\
\hline methylcyclohexane + methyl tert-butyl ether & 0.638 & 0.2 & $\begin{array}{l}1.664 \\
2.516\end{array}$ & 0.4 \\
\hline $\begin{array}{l}\text { 2,2,4-trimethyl pentane }+ \text { methyl tert-butyl ether } \\
\text { tert-butylcycl ohexane }+ \text { methyl tert-butyl ether }\end{array}$ & $\begin{array}{r}-0.072 \\
-0.294 \\
0.438 \\
-0.126 \\
-0.197\end{array}$ & $\begin{array}{l}0.5 \\
0.4\end{array}$ & $\begin{array}{l}1.202 \\
0.216 \\
1.320 \\
3.130\end{array}$ & $\begin{array}{l}0.5 \\
1.0\end{array}$ \\
\hline
\end{tabular}
mental uncertainty.

Table 2. Mathematical Representation of Anthracene Solubilities in Several Binary Alkane (B) + Methyl tert-Butyl Ether (C) Solvent Mixtures

a Combined NIBS/Redlich-Kister curve-fit parameters are ordered as $\mathrm{S}_{0}, \mathrm{~S}_{1}$, and $\mathrm{S}_{2} \cdot{ }^{\mathrm{b}}$ Deviation $(\%)=(100 / 7) \sum \mid\left[\left(x_{A}^{\text {sat }}\right)_{i}^{\text {calc }}-\right.$ $\left.\left(x_{A}^{\text {sat }}\right)_{i}^{\text {exp }}\right] /\left(x_{A}^{\text {sat }}\right)_{i}^{\text {exp }} \mid$. c Adjustable parameters for the modified Wilson equation are ordered as $\Lambda_{B C}^{\text {adj }}$ and $\Lambda_{C B}^{\text {adj }}$. 
From a computational standpoint, eq 1 will likely be preferred because most research groups involved in reporting thermodynamic properties have computer programs for evaluating the Redlich-Kister coefficients. With this idea in mind, we recommend not only that the future presentation of experimental isothermal solubility data for slightly soluble solid solutes dissolved in binary solvent mixtures include a tabulation of the actual observed values but also, if possible, that the solubility data be mathematically represented by eq 1 . Realizing that a single equation will not be applicable to all systems encountered, we further suggest eq 2 as an alternative mathematical representation for systems having extremely large solubility ranges and/ or highly asymmetrical In $x_{A}^{\text {sat }}$ versus $x_{B}^{\circ}$ curves, such as the carbazole + alkane + tetrahydropyran systems reported previously (Acree et al., 1991).

\section{Literature Cited}

Acree, W. E., J r. Mathematical Representation of Thermodynamic Properties. Part 2. Derivation of the Combined Nearly I deal Binary Solvent (NIBS)/-Redlich-Kister Mathematical Representation from a Two-Body and Three-Body Interactional Mixing Model. Thermochim. Acta 1992, 198, 71-79.

Acree, W. E., J r. Polycyclic Aromatic Hydrocarbons in Pureand Binary Solvents. Volume 54 in IUPAC Solubility Data Series; Oxford University Press: Oxford, United Kingdom, 1994.
Acree, W. E., J r. Polycyclic Aromatic Hydrocarbons: Binary Nonaque ous Systems: Part 1 (Solutes A-E). Volume 58 in IUPAC Solubility Data Series; Oxford University Press: Oxford, United Kingdom, 1995a.

Acree, W. E., J r. Polycyclic Aromatic Hydrocarbons: Binary Nonaque ous Systems: Part 2 (Solutes F-Z). Volume 59 in IUPAC Solubility Data Series; Oxford University Press: Oxford, United Kingdom, 1995b.

Acree, W. E., J r.; Rytting, J . H. Solubility in Binary Solvent Systems. III: Predictive Expressions Based on Molecular Surface Areas. J. Pharm. Sci. 1983, 72, 292-296.

Acree, W. E., J r.: Zvaigzne, A. I. Thermodynamic Properties of Nonelectrolyte Solutions. Part 4. Estimation and Mathematical Representation of Solute Activity Coefficients and Solubilities in Binary Solvents Using the NIBS and Modified Wilson Equations. Thermochim. Acta 1991, 178, 151-167.

Acree, W. E., J r.; McCargar, J. W.; Zvaigzne, A. I.; Teng, I.-L. Mathematical Representation of Thermodynamic Properties. Carbazole Solubilities in Binary Alkane + Dibutyl Ether and Alkane + Tetrahydropyran Solvent Mixtures. Phys. Chem. Liq. 1991, 23, $27-35$.

Comer, J . F.; Kopecni, M. M. Prediction of Gas Chromatography Solute Activity Coefficients in Mixed Stationary Phases Based on the Wilson Equation. Anal. Chem. 1990, 62, 991-994.

Weast, R. C., Ed. CRC Handbook of Chemistry and Physics, 64th ed.; CRC Press: Cleveland, $\mathrm{OH}, 1983$.

Received for review May 15, 1996. Accepted J une 26, $1996 .{ }^{\otimes}$

J E960169L

${ }^{\otimes}$ Abstract published in Advance ACS Abstracts, August 1, 1996. 